\title{
Aspek Biologi Cakalang (Katsuwonus pelamis, Linnaeus 1758) di Sulawesi Tenggara
}

\author{
Biological Aspects of Skipjack Tuna in Southeast Celebes
}

Tyas Dwi Bekti Diningrum, Heri Triyono dan Meuthia Aula Jabbar

Sekolah Tinggi Perikanan

JI. AUP Pasar Minggu Jakarta Selatan 12520, Telepon (021) 7806874 fax (021) 7805030

\begin{abstract}
Abstrak
Ikan Cakalang (Katsuwonus pelamis) merupakan salah satu jenis ikan ekonomis yang ditangkap dengan berbagai macam alat tangkap di di Sulawesi Tenggara. Penelitian dilakukan bulan Maret hingga Mei 2019 di Perairan Sulawesi Tenggara. Penelitian ini bertujuan untuk mengetahui aspek biologi ikan cakalang yang meliputi hubungan panjang-bobot, sex ratio, Tingkat Kematangan Gonad (TKG), panjang ikan pertama kali tertangkap (LC), ukuran pertama kali matang gonad (Lm) serta mengetahui daerah penangkapan dan musim penangkapan ikan cakalang. Metode yang digunakan adalah accidental sampling untuk penentuan responden yang diwawancarai, metode simple random sampling untuk menentukan ikan contoh. Hasil penelitian menunjukkan bahwa hubungan panjang berat ikan cakalang jantan besifat isometrik dengan persamaan $\mathrm{W}=0,0189 \mathrm{~L}^{3}$, sedangkan pola pertumbuhan cakalang betina bersifat alometrik negatif dengan persamaan $\mathrm{W}=$ $2,83 L^{1,69}$. Nisbah kelamin didominasi oleh Jantan dengan perbandingan 1:0,4. Tingkat Kematangan Gonad didominasi oleh ikan immature (TKG I dan II). Didapatkan Lm $=47,73 \mathrm{~cm}$ $(34,10-66,78)$. Lc $<$ Lm pada alat tangkap purse seine dan Lc $>$ Lm pada alat tangkap pancing tonda dan huhate. cakalang paling banyak tertangkap di Laut Banda pada musim barat (September-Februari) dan di Teluk Bone saat musim timur (Maret-Agustus). Sumberdaya perikanan cakalang diindikasi mengalami overfishing dilihat dari banyaknya ikan immature yang tertangkap dan nilai Lc (purse seine) yang lebih kecil dari pada Lm-nya. Rekomendasi hasil penelitian adalah agar nelayan beralih alat tangkap dari purse seine ke pancing tonda atau huhate.
\end{abstract}

Kata kunci: ikan tangkapan, nelayan, sumberdaya perikanan

\section{Abstract}

Skipjack fish (Katsuwonus pelamis) is one of the economical types of fish caught with a variety of fishing gear in Southeast Sulawesi. The study was conducted from March to May 2019 in the waters of Southeast Sulawesi. This study aims to determine the biological aspects of skipjack fish which includes the relationship of length-weight, sex ratio, Gonad Maturity Level (TKG), the length of the fish first caught (Lc), the size of the first gonad ripe $(\mathrm{Lm})$ as well as knowing the area of capture and fishing season skipjack fish. The method used was accidental sampling to determine the respondents interviewed, a simple random sampling method to determine sample fish. Lc calculations using the results of the study show that the long-weight relationship of male skipjack tuna isometric with the equation $\mathrm{W}=0.0189 \mathrm{~L} 3$, while the female skipjack growth pattern is negative allometric with the equation $\mathrm{W}=2.83 \mathrm{~L} 1.69$. The sex ratio is dominated by males with a ratio of 1: 0.4 . Gonad Maturity Level is dominated by immature fish (TKG I and II). Obtained Lm $=47.73 \mathrm{~cm}(34.10-66.78)$. LC $<\mathrm{Lm}$ on purse seine fishing gear and LC> Lm on trolling and huhate fishing gear. skipjack tuna is most caught in the Banda Sea in the west season (SeptemberFebruary) and in the Gulf of Bone during the east season (March-August). Skipjack fisheries resources are indicated to be overfishing as seen from the number of immature fish caught and Lc (purse seine) values smaller than the $\mathrm{Lm}$. The recommended results of the study are for fishermen to switch fishing gear from purse seine to trolling or huhate fishing line. 
Penulis Korespondensi

Tyas Dwi Bekti Diningrum | diningrumtyas97@gmail.com

\section{PENDAHULUAN}

Ikan Cakalang (Katsuwonus pelamis) merupakan salah satu jenis ikan ekonomis penting, potensial dan banyak dimanfaatkan oleh masyarakat nelayan. Ikan ini ditangkap dengan menggunakan berbagai macam alat tangkap di di Sulawesi Tenggara. Jatmiko, Hartaty, dan Bahtiar (2015) menyampaikan bahwa produksi ikan cakalang di Indonesia selama tahun 2001-2010 adalah yang terbesar sebanyak $52 \%$ dari total produksi kelompok ikan tuna lainnya (Madidihang, tuna mata besar, albacore dan tuna sirip biru).

Cakalang merupakan highly migratory spesies yang terdistribusi di perairan tropis dan subtropis (Collette dan Nauen 1983). Spesies ini melakukan beberapa kali pemijahan pada daerah dimana suhu permukaan laut lebih tinggi dari $24{ }^{\circ} \mathrm{C}$ (Matsumoto, Skillman, dan Dizon 1984).Cakalang terdistribusi di Samudera Pasifik bagian barat mulai dari bagian utara Jepang sampai ke Selandia Baru bagian selatan dan terdistribusi di perairan negara-negara di kawasan pasifik seperti Kepulauan Solomon, Papua Nugini dan Perairan Irian Jaya utara (Comitini dan Hardjolukito 1986).

\section{Pengelolaan}

perikanan berkelanjutan membutuhkan empat data pendukung utama yakni data biologi ikan, ekologi, ekonomi dan sosial (Masuswo dan Widodo 2016). Penelitian ini bertujuan untuk mengetahui aspek biologi ikan cakalang di Sulawesi Tenggara yang meliputi hubungan panjang-bobot, sex ratio, Tingkat Kematangan Gonad (TKG), Lc, Lm serta mengetahui daerah penangkapan dan musim penangkapan ikan cakalang.

\section{BAHAN DAN METODE}

\section{Lokasi dan desain penelitian}

Penelitian ini dilaksanakan pada bulan Maret-Mei 2019 pada 8 titik pengambilan sampel di Sulawesi Tenggara yakni: PPS Kendari, PPI Sodohoa, Pulau wangi-wangi, Pulau Tomia, Wameo Bau-bau, Pasarwajo, Lasalimu Selatan dan Kolaka.

\section{Metode Pengumpulan data}

Responden yang akan diwawancarai ditentukan menggunakan metode accidental sampling, yakni dipilih nelayan penangkap ikan cakalang di perairan Sulawesi Tenggara yang dijumpai di semua titik lokasi 
pengambilan sampel dan memiliki pengalaman melaut selama 10 tahun. Ikan contoh yang digunakan diambil dengan metode simple random sampling yakni mengukur $10 \%$ dari total ikan yang didaratkan oleh satu kapal penangkap.

\section{Analisis data}

Model yang digunakan dalam menduga hubungan panjang dan bobot merupakan hubungan eksponensial dengan persamaan sebagai berikut (Andamari, Hutapea, dan Prisantoso Iskandar 2012):

$$
\mathrm{W}=\mathrm{a} \mathrm{L}^{\mathrm{b}}
$$

Keterangan :

W : Bobot ikan (gram)

$\mathrm{L}$ : Panjang standar/cagak ikan (cm)

a : Bilangan konstanta atau intercept yang dicari dari perhitungan regresi

b : Eksponen atau sudut tangesial

Perbandingan jenis kelamin diketahui dengan menggunakan rumus: $Y=\frac{Y}{(X+Y)} \times 100 \%$; dan $X=\frac{X}{(X+Y)} \times 100 \%$ Keterangan:

$\mathrm{Y}=$ Jumlah Ikan JantanX = Jumlah Ikan Betina

Ukuran pertama kali matang gonad (Lm) dapat diduga dengan rumus Soerman-Karber yang diusulkan oleh Udupe (1986) sebagai berikut:

$$
m=x k+\frac{d}{2}-\left(X \sum P i\right)
$$

Keterangan:

$\mathrm{m}$ : logaritma dari kelas panjang pada kematangannya yang pertama

d : selisih logaritma dari pertambahan nilai tengah panjang $\mathrm{k}$ : jumlah kelas panjang

xk : logaritma nilai tengah panjang dimana ikan $100 \%$ matang gonad (atau dimana $\mathrm{pi}=1$ ).

Panjang ikan pertama kali tertangkap (Lc) diduga melalui metode Sparre dan Venema (1999) :

$$
S L=\frac{1}{a+\exp (a-b L)}
$$

Nilai $\mathrm{LC}_{50 \%}$ diperoleh dengan memplotkan presentase frekuensi kumulatif ikan yang tertangkap dengan ukuran panjang standarnya, dimana titik potong antara kurva 50\% frekuensi kumulatif adalah panjang saat $50 \%$ ikan tertangkap. Adapun nilai Lc dapat dihitung melalui rumus:

$$
L c=\frac{-a}{b}
$$

Tingkat kematangan gonad ditentukan melalui pengamatan visual terhadap morfologis gonad. Selanjutnya ciri-ciri yang teramati disesuaikan dengan ciriciri tingkat kematangan gonad. Ikan berdasarkan ciri morfologi gonad yang dikembangkan oleh Cassie dan dimodifikasi oleh Effendie (1979). 
Tabel 1. Tingkat Kematangan Gonad Cakalang dan Tongkol (Effendie 1979)

\begin{tabular}{cll}
\hline TKG & \multicolumn{1}{c}{ JANTAN } & \multicolumn{1}{c}{ BETINA } \\
\hline I & $\begin{array}{l}\text { Testis seperti benang, lebih } \\
\text { pendek, ujungnya di rongga tubuh, } \\
\text { transparan }\end{array}$ & $\begin{array}{l}\text { Ovari seperti benang, panjang } \\
\text { sampai ke depan tubuh, } \\
\text { transparan, permukaan licin }\end{array}$ \\
II $\quad \begin{array}{l}\text { Ukuran testis lebih besar, } \\
\text { pewarnaan putih susu, bentuk lebih } \\
\text { jelas dari TKG I }\end{array}$ & $\begin{array}{l}\text { Ukuran lebih besar, pewarnaan } \\
\text { gelap kekuningan, telur belum } \\
\text { terlihat jelas }\end{array}$ \\
III $\quad \begin{array}{l}\text { Permukaan testis nampak } \\
\text { bergerigi, warna makin putih, dalam } \\
\text { keadaan diawetkan mudah putus. }\end{array}$ & $\begin{array}{l}\text { Ovari berwarna kuning, secara } \\
\text { morfologi telur sudah kelihatan } \\
\text { butirnya dengan mata. }\end{array}$ \\
IV & $\begin{array}{l}\text { Seperti TKG III tampak lebih jelas } \\
\text { testis makin pejal dan rongga tubuh } \\
\text { mulai penuh, warna putih susu }\end{array}$ & $\begin{array}{l}\text { Ovari makin besar, telur berwarna } \\
\text { kuning, mudah dipisahkan, butir } \\
\text { minyak tak tampak, mengisi 1/2- } \\
\text { 2/3 rongga tubuh, usus terdesak }\end{array}$ \\
& $\begin{array}{l}\text { Testis bagian belakang kempis dan } \\
\text { bagian dekat pelepasan masih } \\
\text { berisi. }\end{array}$ & $\begin{array}{l}\text { Ovari berkerut, dinding tebal, butir } \\
\text { telur sisa terdapat di dekat } \\
\text { pelepasan. Banyak telur seperti } \\
\text { pada tingkat II }\end{array}$ \\
\hline
\end{tabular}

\section{HASIL DAN PEMBAHASAN}

\section{Distribusi Frekuensi Panjang}

Berdasarkan hasil pengamatan terhadap 1016 ekor ikan contoh diperoleh maksimal panjang ikan $73 \mathrm{~cm}$ dan minimal $20 \mathrm{~cm}$, maksimal bobot ikan 8680 gr dan minimal 131 gr. Data sebaran distribusi frekuensi panjang ikan contoh didominasi oleh panjang kelas 45 - 49 cm (187 ekor). Sedangkan ikan contoh jantan didominasi oleh panjang kelas $44-48 \mathrm{~cm}$ (36 ekor) dan betina didominasi oleh 44 - $49 \mathrm{~cm}$ (19 ekor).

Ikan cakalang banyak tertangkap pada kisaran panjang $44-46 \mathrm{~cm}$ baik dari jenis jantan maupun betina. Hal ini karena kegiatan penangkapan cakalang di Sulawesi Tenggara menggunakan alat bantu yakni rumpon. Rumpon biasanya menjadi habitat untuk gerombolan juvenile ikan. Pada lokasi yang sama (Laut Banda) Husair et al. (2015) mendapatkan kisaran panjang cakalang yang ditangkap dari rumpon berkisar antara $41-59,3 \mathrm{~cm}$.

\section{Hubungan Panjang Bobot}

Pada ikan contoh jantan didapatkan nilai $\mathrm{a}=0,0075$ dan nilai $\mathrm{b}=$ 3,240 . Hasil uji t terhadap nilai b pada selang kepercayaan 95\% didapatkan nilai t hitung $=-2,030$ dan $\mathrm{t}$ tabel $=1,99$. Diketahui nilai t hitung $<\mathrm{t}$ tabel, hal ini berarti $\mathrm{H}_{0}$ diterima yang berarti pola 
pertumbuhan ikan cakalang jantan diduga bersifat isometrik. Setelah dilakukan uji lanjutan maka persamaan hubungan panjang bobot ikan cakalang jantan adalah $\mathrm{W}=0,0189 \mathrm{~L}^{3}$ yang berarti setiap pertambahan bobot sebesar $\mathrm{W}$ maka akan bertambah panjang sebesar $0,0189 \mathrm{~L}^{3}$. Pola pertumbuhan isometrik berarti pertumbuhan panjang ikan beriringan dengan pertumbuhan bobotnya. Dengan nilai koefisien korelasi $(r)=0,95$ yang mendekati 1 berarti pertumbuhan panjang akan selalu mempengaruhi pertumbuhan bobotnya.

Pada ikan contoh betina didapatkan nilai $a=2,833$ dan nilai $b=$ 1,699. Hasil uji t terhadap nilai b pada selang kepercayaan 95\% didapatkan nilai $t$ hitung $=3,092$ dan nilai $t$ tabel 2,042 . Diketahui t hitung $>t$ tabel hal ini berarti pola pertumbuhan ikan cakalang betina diduga bersifat allometrik dan dengan nilai b $(1,699)<3$ maka pertumbuhan pola ikan cakalang betina diduga bersifat allometrik negatif yakni pertumbuhan panjang ikan lebih cepat dari bobotnya. Persamaan panjang bobot ikan contoh cakalang betina adalah $\mathrm{W}=2,83 \mathrm{~L}^{1,69}$ yang berarti setiap pertambahan bobot sebesar W maka akan bertambah panjang sebesar 2,83 $L^{1,69}$. Keadaan ini sama dengan yang didapatkan oleh Nugraha et al. (2010) di mana pola pertumbuhan ikan cakalang yang didaratkan di Tulehu Ambon bersifat allometrik negatif dengan persamaan $\mathrm{W}=0,0485 \mathrm{~L}^{2,751}$.

\section{Sex Ratio}

Dari 1016 ikan contoh, 109 ekor diantaranya dibedah dan diamati jenis kelaminnya. Diperoleh sebanyak 77 (69\%) ekor jantan dan 32 (31\%) ekor betina. Dengan sex ratio 1:0,4. Untuk mengetahui apakah populasi ikan cakalang berada dalam kondisi ideal untuk mempertahankan kelestariannya dengan asumsi bahwa satu ikan jantan akan memijahi satu ikan betina, maka perlu dilakukan pengujian terhadap nilai sex ratio yang bernilai $1: 0,4$ apakah bernilai 1:1. Pengujian ini menggunakan uji chi kuadrat dengan derajat bebas (db) = 1 dan taraf kepercayaan $95 \%$. Dari perhitungan nisbah kelamin dapat dilihat bahwa nilai chi-kuadrat $\left(\mathrm{x}^{2}\right)$ hitung yang diperoleh adalah sebesar 18,58 lebih besar dari nilai chi-kuadrat $\left(x^{2}\right)$ Tabel sebesar 3,84, itu berarti $x 2$ hitung $>x^{2}$ tabel. Kondisi ini menunjukkan bahwa $\mathrm{H}_{0}$ ditolak, $\mathrm{H}_{1}$ diterima yang artinya perbandingan antara jantan dan betina bukan 1:1. Sehingga dapat disimpulkan bahwa terdapat perbedaan yang nyata antara cakalang jantan dan betina dimana cakalang jantan lebih banyak dari pada betinanya dengan perbandingan 1:0,4 


\section{Tingkat Kematangan Gonad}

Ikan cakalang yang menjadi ikan contoh selama praktik akhir berjumlah 109 ekor terdiri dari 77 ekor jantan dan 32 ekor betina. Cakalang jantan terdiri dari TKG I sebanyak 7 ekor ( 9\%), TKG II sebanyak 44 ekor (57\%), TKG III sebanyak 19 ekor (25\%) dan TKG IV sebanyak 7 ekor (9\%). Dilihat bahwa cakalang yang berada dalam kondisi sedang matang gonad ( TKG III dan IV) sebanyak 26 ekor atau $34 \%$ dari jumlah cakalang jantan tersebut, kemudian sebanyak 51 ekor atau $66 \%$ berada dalam kondisi belum matang gonad (TKG I dan II). Berdasarkan data tersebut, ikan yang tertangkap lebih banyak yang belum matang gonad dibandingkan dengan yang sudah matang gonad.

Cakalang betina terdiri dari TKG I sebanyak 7 ekor (22\%), TKG II sebanyak 10 ekor (31\%), TKG III sebanyak 10 ekor (31\%) dan TKG IV sebanyak 5 ekor (16\%). Dapat dilihat bahwa ikan yang berada dalam kondisi sedang matang gonad ( TKG III dan IV) sebanyak 15 ekor atau $47 \%$ dari jumlah cakalang betina tersebut, kemudian sebanyak 17 ekor atau $53 \%$ berada dalam kondisi belum matang gonad (TKG I dan II). Berdasarkan data tersebut menunjukan bahwa ikan yang belum matang gonad tertangkap lebih banyak dari yang sudah matang gonad.
Secara keseluruhan didapatkan TKG I sebanyak 14 ekor ( 13\%), TKG II sebanyak 54 ekor (49\%), TKG III sebanyak 29 ekor (27\%) dan TKG IV sebanyak 12 ekor (11\%). Dapat dilihat bahwa ikan yang berada dalam kondisi sedang matang gonad ( TKG III dan IV) sebanyak 41 ekor atau $38 \%$, kemudian sebanyak 68 ekor atau $62 \%$ berada dalam kondisi belum matang gonad (TKG I dan II). Berdasarkan data tersebut menunjukan bahwa ikan yang belum matang gonad tertangkap lebih banyak dari yang sudah matang gonad.

Keadaan ini tidak sama dengan yang didapatkan oleh Jatmiko et al. (2015) yang mendapatkan ikan cakalang dalam keadaan matang gonad lebih banyak dari yang belum matang gonad di perairan Samudera Hindia bagian timur.

\section{Lenght at First Maturity}

Hasil pengamatan yang dilakukan untuk tingkat kematangan gonad dan sebaran ukuran panjang terhadap 109 ekor ikan contoh, diduga panjang pertama kali matang gonad adalah 47,73 $\mathrm{cm}$ dan dengan menggunakan taraf kepercayaan 95\%, maka batas kepercayaan untuk prediksi ikan cakalang adalah $34,10-66,78 \mathrm{~cm}$ sehingga didapatkan nilai $\mathrm{Lm}=47,73$ $(34,10-66,78)$. 


\section{Lenght at First Capture}

Perhitungan Lc dilakukan dengan menggunakan data sebaran panjang dan jumlah ikan pada tiap sebaran panjang pada setiap alat tangkap. Berdasarkan hasil pengamatan terhadap 331 ekor ikan contoh yang tertangkap oleh purse seine, didapatkan ukuran pertama kali tertangkap ikan cakalang adalah 30,7 $\mathrm{cm}$. Kemudian hasil pengamatan terhadap terhadap 685 ekor ikan contoh yang tertangkap oleh alat tangkap pancing (pancing tonda, pancing ulur dan huhate) didapatkan rata-rata ukuran ikan yang tertangkap $47,9 \mathrm{~cm}$. nilai ini tidak jauh berbeda dengan yang didapatkan oleh Nugraha dan Rahmat (2008) di perairan Bitung Sulawesi Utara dimana didapatkan nilai Lc Cakalang yang tertangkap huhate adalah 49,3 cm.

Disebutkan dalam fishbase ukuran pertama kali matang gonad (Lm) cakalang (Katsuwonus pelamis) adalah $40,0 \mathrm{~cm}$ atau kisaran panjang $40-45 \mathrm{~cm}$ dan pada praktik ini didapatkan nilai Lm $=47,73$ atau kisaran panjang 34,10 $66,78 \mathrm{~cm}$. Alamsyah dan Musbir (2014) mendapatkan nilai Lm cakalang $=58,79$ (jantan) dan 54,13 (betina) di Perairan Teluk Bone. Berdasarkan data dari beberapa referensi maka didapatkan nilai Lm cakalang (Katsuwonus pelamis) berkisar antara $40-60 \mathrm{~cm}$.

Dari Lc yang didapatkan dalam penelitian ini yakni $30,7 \mathrm{~cm}$ pada alat tangkap purse seine di ketahui bahwa $\operatorname{Lc}<\operatorname{Lm}(30,7 \mathrm{~cm}<40-60 \mathrm{~cm})$ yang menandakan bahwa cakalang yang tertangkap dengan alat tangkap purse seine yakni 379 ekor atau sekitar 37,3\% dari total ikan contoh diduga belum sempat memijah sebelum tertangkap. Sedangkan ukuran rata-rata ikan yang tertangkap dengan alat tangkap pancing yakni 47,9 cm di ketahui bahwa Lc $\geq \mathrm{Lm}$ $(47,9 \mathrm{~cm} \geq 40-60 \mathrm{~cm})$ yang menandakan bahwa cakalang yang tertangkap dengan alat tangkap pancing diduga sudah pernah memijah sebelum tertangkap.

Ikan yang tertangkap dengan alat tangkap pancing telah atau sedang memasuki ukuran matang gonad, sehingga pancing diperkirakan lebih selektif dari purse seine. Untuk itu disarankan mengurangi alat tangkap purse seine dan menggantinya dengan alat tangkap pancing agar ikan mendapat kesempatan untuk memijah sebelum tertangkap.

\section{Daerah dan Musim Penangkapan}

Berdasarkan hasil wawancara, daerah penangkapan di Sulawesi Tenggara berada pada 2 WPP yakni WPP 713 dan WPP 714 dengan musim ikan yang berlawanan, nelayan di Kendari dan semua kota atau daerah yang berada pada sisi timur Sulawesi Tenggara (WPP 714) banyak menangkap ikan saat musim barat yakni 
bulan September-Februari. Sedangkan nelayan di wilayah Kolaka dan semua daerah yang berada pada sisi barat Sulawesi Tenggara (WPP 713) banyak menangkap ikan saat musim timur yakni pada bulan Maret-Agustus.

\section{SIMPULAN DAN SARAN}

Cakalang memiliki pola pertumbuhan yang bersifat isometrik, diindikasikan mengalami overfishing karena $\mathrm{L} c<\mathrm{Lm}$ dan tingkat kematangan gonad yang didominasi oleh ikan immature dan didapatkan jantan lebih banyak dengan perbandingan 1:0,4. Daerah penangkapan di Sulawesi Tenggara adalah di Teluk bone (WPP 713) dan Laut Banda (WPP 714). Musim ikan untuk daerah Kendari dan sekitarnya adalah pada bulan September-Februari dan di daerah Kolaka dan sekitarnya pada bulan MaretAgustus.

\section{DAFTAR PUSTAKA}

Alamsyah, Ridha dan Faisal A. Musbir. 2014. "Struktur Ukuran dan Ukuran Layak Tangkap Ikan Cakalang (Katsuwonus Pelamis) di Perairan Teluk Bone." Jurnal Ipteks Pemanfaatan Sumberdaya Perikanan 2(1):11-20.

Andamari, Retno, Jhon Haryanto Hutapea, dan Budi Prisantoso Iskandar. 2012. “Aspek Reproduksi
Ikan Tuna Sirip Kuning (Thunnus albacares)." Jurnal IImu dan Teknologi Kelautan Tropis 4(1):8996.

Collette, Bruce B. dan Cornelia E. Nauen. 1983. FAO Species Catalogue Vol. 2 Scombrids Of The World An Annotated and Illustrated Catalogue of Tunas, Mackerels, Bonitos and Related Species Known to Date. Rome (IT): Food and Agriculture Organization of The United Nations.

Comitini, Salvatore dan Sutanto Hardjolukito. 1986. "Economic benefits and costs of alternative arrangements for tuna fisheries development in the exclusive economic zone: The case of Indonesia." Ocean Management 10(1):37-55.

Effendie, M. I. 1979. Metoda Biologi Perikanan. Bogor (ID): Yayasan Dewi Sri.

Husair, Muslim T., La Anadi Abdullah, A. Mustafa, dan H. Arami. 2015. "Analisis Hasil Tangkapan Ikan Cakalang (Katsuwonus pelamis) Pada Daerah Penangkapan dengan Menggunakan Rumpon dan Tanpa Rumpon di Perairan Barat Laut Banda." Hal. 1238 in Prosiding Simposium Nasional Pengelolaan Perikanan Tuna Berkelanjutan. Bali (ID). 
Jatmiko, Irwan, Hety Hartaty, dan Andi Bahtiar. 2015. "Biologi reproduksi ikan cakalang (Katsuwonus pelamis) di Samudera Hindia bagian Timur." BAWAL Widya Riset Perikanan Tangkap 7(2):8794.

Masuswo, Rudy dan Agustinus Anung Widodo. 2016. "Karakteristik biologi ikan tongkol komo (Euthynnus affinis) yang tertangkap jaring insang hanyut di Laut Jawa." BAWAL Widya Riset Perikanan Tangkap 8(1):57-63.

Matsumoto, Walter M., Robert A. Skillman, dan Andrew E. Dizon. 1984. Synopsis of biological data on skipjack tuna, Katsuwonus pelamis.

Nugraha, Budi dan Enjah Rahmat. 2008. "Status perikanan huhate (pole and line) di Bitung, Sulawesi Utara." Jurnal Penelitian Perikanan Indonesia 14(3):313-20.

Sparre, Per dan Siebren C. Venema. 1999. Introduksi pengkajian stok ikan tropis: Buku I Manual. diedit oleh W. J, M. IGS, N. S, B. M, dan Penerjemah. Pusat Penelitian dan Pengembangan Perikanan.

Udupe, K. S. 1986. "Statistical method of estimating the size at first maturity in fishes." Fishbyte 4(2):8-10. 